\title{
Prevalence of Schistosoma japonicum in bovines and Oncomelania hupensis quadrasi from ricefields surrounding Lake Mainit, Philippines
}

\author{
Joycelyn C. Jumawan ${ }^{1}$ Leonardo A. Estaño ${ }^{1}$
}

Received: 11 November 2020/Accepted: 1 March 2021/Published online: 15 March 2021

(C) Indian Society for Parasitology 2021

\begin{abstract}
Schistosomiasis is a parasitic disease caused by blood flukes of the genus Schistosoma and involves bovines and snails as a reservoir and intermediate hosts, respectively. This disease is endemic in Lake Mainit, Philippines, as early as 1947 . The study was conducted to determine the prevalence of Schistosoma infection in ricefields adjacent to Lake Mainit by collecting Oncomelania hupensis quadrasi snails and bovine fecal samples which are then subjected to laboratory examination and analysis. A total of 345 O. quadrasi individuals and 32 bovine fecal samples were collected from six barangay rice field stations adjacent to Lake Mainit from February and July 2020. Among the six barangays, Alipao had the highest prevalence of Schistosoma in $O$. quadrasi $(39.71 \%)$, followed by San Isidro (28.3\%), Matin-ao (18\%), Poblacion (15\%), and Magpayang (2.5\%). No Oncomelania snails were collected in the ricefields of Cuyago. Schistosoma japonicum had an overall prevalence of $14.71 \%$ in all the bovines sampled, where Cuyago had the highest prevalence $(50.0 \%)$ followed by Alipao (33.33\%). The intensity of infection of Schistosoma eggs per gram $(\mathrm{MPEG}=0.70)$ among bovines is categorized as light. Bovine contamination index calculations revealed that, on average, infected bovines in Lake Mainit excrete $55,000 \mathrm{~S}$. japonicum eggs per day. The study confirms the important role of bovines as a reservoir host for schistosomiasis. The presence of both infected bovines and $O$. quadrasi in ricefields makes this agricultural venue an
\end{abstract}

Joycelyn C. Jumawan

joycejumawan1981@gmail.com

1 Department of Biology, College of Mathematics and Natural Sciences, Caraga State University, Butuan City, Agusan Del Norte, Philippines important nidus of S. japonicum emergence in Lake Mainit. An integrated approach of mass drug administration (MDA) of praziquantel, implementation of a bovine vaccine-directed control program, and providing farmers with mechanized farm equipment are highly recommended to minimize the risk of exposure and infection to schistosomiasis in rice fields adjacent to the lake.

Keywords Bovines - Schistosomiasis · Lake Mainit · Prevalence

\section{Introduction}

Schistosomiasis is a disease caused by trematode parasites of the genus Schistosoma. Schistosoma japonicum uses snails, primarily Oncomelania hupensis quadrasi, as an intermediate host for the disease affecting 78 countries including the Philippines (Carabin 2005; Leonardo et al. 2016). More than 220 million people are estimated to be infected by this disease, predominantly in low-income and middle-income countries (Colley et al. 2014). Bovines have been identified as the primary reservoir host of $S$. japonicum infection in China (McManus et al. 2011; Gray et al. 2009a) as infected water buffaloes and cattle could excrete up to $60 \mathrm{~kg}$ of stool per individual (Gray et al. 2009b). Early epidemiologic surveys conducted in 50 villages in Samar, Philippines have indicated that water buffaloes (carabao) are unimportant in transmission (Fernandez et al. 2007; Riley et al. 2008) perhaps due to uncertain species-specific test characteristics of the diagnostic method used. However, a high prevalence of $S$. japonicum in the carabao from Samar Province was reported using a validated real-time PCR (qPCR) and the 
Fig. 1 Map of selected rice fields in Lake Mainit, Philippines

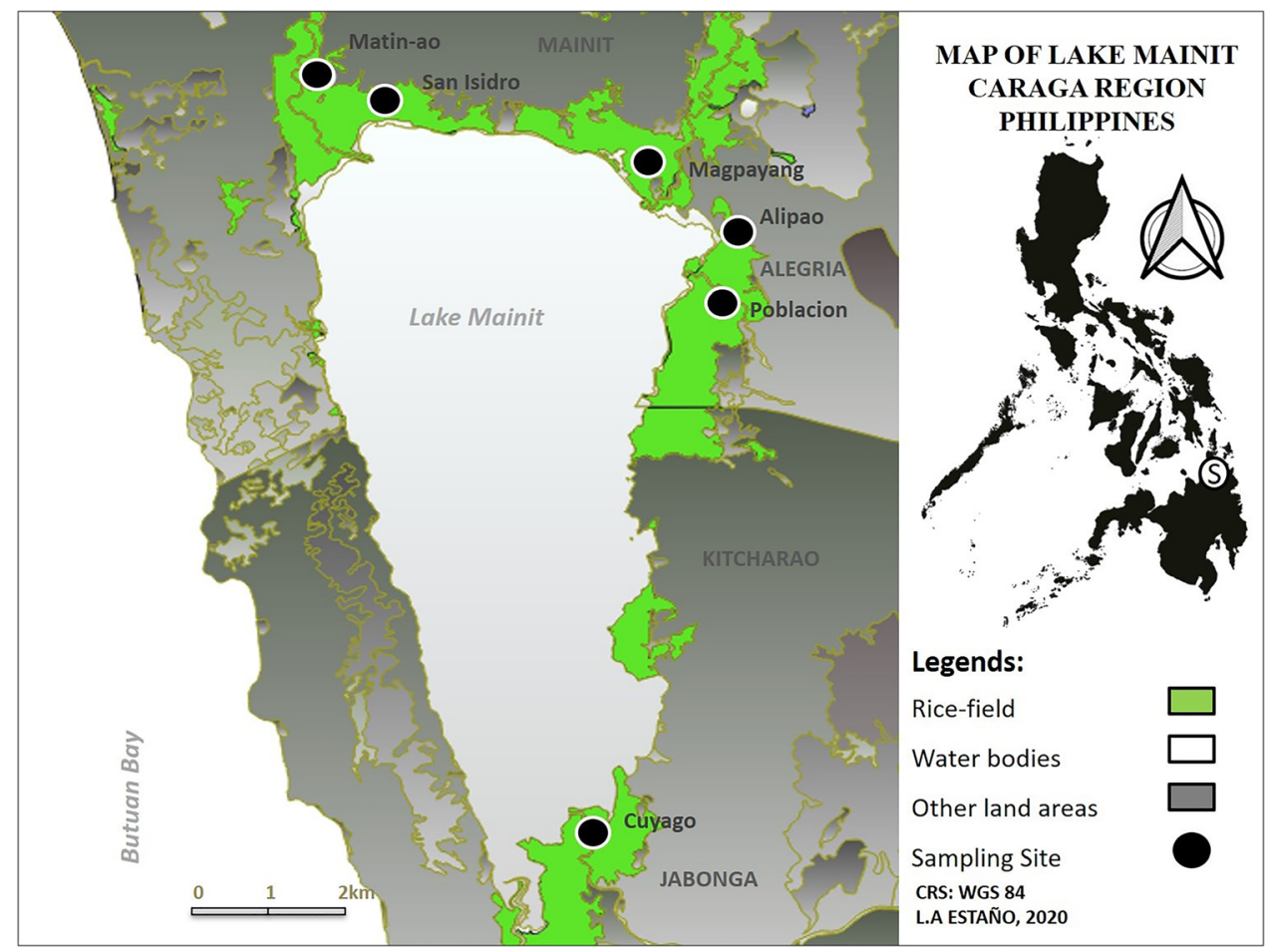

formalin-ethyl acetate sedimentation (FEA-SD) technique (Gordon et al. 2012).

Lake Mainit is the fourth largest and the deepest lake in the Philippines adjoining almost equally the two provinces, namely Agusan del Norte and Surigao del Norte (Cassion et al. 2013; Jumawan et al. 2016). The lake is recognized as one of the key biodiversity areas in the country having sheltering threatened wildlife (Demetillo et al. 2016). Rice fields are strategically situated near the lake's shorelines and are often extensively flooded during rainy months. The most common livelihood practices observed in areas surrounding the lake mainly involve farming, fishing, livestock, and poultry production, mainly of native ducks (Cassion et al. 2013; Abao-Paylangco et al. 2019). Reports of schistosomiasis cases are still persistent due to continuous transmission in areas surrounding the lake. These have been attributed to the presence of the snail intermediate hosts, which could be the source of infections towards the human inhabitants (LMDA 2005; Cassion et al. 2013; Abao-Paylangco et al. 2019).

Occupational risk of schistosomiasis includes exposure to water bodies (irrigated canals, rice paddies, swamps, residential areas) where snails and bovines thrive (Jumawan et al., 2016). Moreover, the availability of research findings focusing on the direct link of $O$. hupensis-quadrasi and bovines in ricefields adjacent to Lake Mainit to human schistosomiasis remains limited.

This study aims to determine the prevalence of Schistosoma japonicum infection in Oncomelania hupensis quadrasi and bovines in the rice fields at Lake Mainit. The Bovine Contamination Index (BCI) of Schistosoma infection was also determined to understand the link of the intermediate and reservoir hosts as key players in the transmission of schistosomiasis in Lake Mainit.

\section{Materials and methods}

\section{The locale of the Study}

A cross-sectional survey for the collection of bovine feces and $O$. quadrasi snails covered two cropping seasons and was conducted in the months of February and July 2020. The selection of study stations considered the areas with $O$. hupensis quadrasi occurrence and bovines as reported by other studies (Jumawan et al. 2016; Abao-Paylangco et al. 2019). Six study stations were established in the following barangays: Alipao and Poblacion for the Municipality of Alegria, Surigao del Norte; Magpayang, San Isidro, and Matin-ao for the Municipality of Mainit, Surigao del Norte; and lastly Cuyago for the Municipality of Jabonga, Agusan del Norte (Fig. 1).

\section{Collection of Oncomelania hupensis-quadrasi}

Wildlife Gratuitous Permit (WGP) R13-2019-65 of the Department of Environment and Natural Resources (DENR) was secured prior to the collection of snails. A 
$100 \mathrm{~m}$ triplicate transect was set along the selected rice fields to perform the collection of viable $O$. quadrasi-hupensis snails which were handpicked using fine thumb forceps. Snail collection was done in a semi-purposive sampling and was done between 6:00-10:00 in the morning with approximately thirty minutes allotted per study station to avoid bias (Opisa et al. 2011; Leonardo et al. 2013; Jumawan et al. 2016). Oncomelania snails were individually placed in transparent $30 \mathrm{ml}$ vials covered with a mesh net $\left(4^{\prime \prime} \times 4^{\prime \prime}\right.$ in.) before transport to the laboratory for cercarial shedding. Coordinates from Global Positioning System (GPS) was used for the spatial distribution analysis of schistosomiasis infection of Oncomelania snails and bovine fecal samples were mapped out using ArcGIS (Fig. 2).

\section{Artificial shedding and isolation of Schistosoma japonicum cercaria}

The Oncomelania snails were sorted based on the site of collection. The snails were subjected to an artificial cercarial shedding technique (Opisa et al. 2011), exposing snails to direct sunlight between 8:00 am-12:00 pm. Water from the individual vials was examined for shed cercaria using a compound microscope before snail examination. Snails were crushed using two glass slides (Kariuki et al. 2004; Opisa et al. 2011) and added two drops of distilled water and viewed using a compound microscope. Schistosoma japonicum cercaria is distinctly brevifurcate-apharyngeate distome furcocercarial type with the tail furcae curved backwardly when observed in open water (Frandsen and Christensen 1984).

\section{Bovine fecal samples collection}

Bovine fecal samples, regardless of species, were collected simultaneously on the same day and study stations where snails were collected. Fecal samples collected in the rice fields came from the Philippine water buffaloes (Bubalus bubalis) and Philippine cattle (Bos sp.) and were collectively called bovines. Before collection, the bovines were screened for the following criteria: (1) bovines to be sampled must be grazed, bathed, and exposed in the ricefields where feces are collected and (2) freshness of the deposited feces must not be later than $24 \mathrm{~h}$ prior for formalin preservation. Freshly deposited feces were collected and identified as a viable sample for fecalysis. Only 3-5 g from a bovine fecal sample were collected and was placed in a stool container with $3 \mathrm{ml} \mathrm{10 \%} \mathrm{formalin} \mathrm{for} \mathrm{preserva-}$ tion (Jumawan et al. 2020).

\section{Modified formalin ethyl-acetate sedimentation digestion (FEA-SD) technique}

The study used the stool parasitological examination technique modified by Tenorio and Molina (2020) employing the novel copro-parasitological technique as described by $\mathrm{Xu}$ et al. (2012) for the detection of $S$. japonicum eggs in bovine fecal samples, the FEA-SD with few modifications. The whole volume of the sample was read using a modified McMaster Egg Counting Chamber.

\section{Statistical analysis}

The prevalence of $S$. japonicum infection in bovines was determined based on the presence of schistosome eggs in fecal samples. Egg counts in $5 \mathrm{~g}$ of feces were noted. The collected bovine fecal samples and snails among stations were tested in their significant association with the prevalence of $S$. japonicum infection. This was explored using Chi-square independent test. All data were tested for normality of distribution using SPSS v. 20.0 software (IBM Corp., 2011) applying a 95\% confidence level. The Shapiro-Wilk test was used to determine the normality of the data collected in the study. Statistical computations were performed using Quantitative Parasitology (QP) version 3.0.

The Prevalence rate of Schistosoma japonicum in collected snail and bovine per sites was determined using the following formula:

$$
\text { Prevalence }(\%)=\frac{\text { No. of infected samples }}{\text { Total Number of Collected Samples }}
$$

Additionally, infection intensity of bovines within each endemic setting was determined based on the total egg count in $5 \mathrm{~g}$ of fecal samples. The intensity of infection was determined by egg counts in $5 \mathrm{~g}$ of feces and was categorized as light (1-400 eggs), moderate (101-400 eggs), or heavy ( $>400$ eggs), as described by Tenorio and Molina (2020). The mean of the egg counts among sites was subjected to a Kruskal Wallis test for equality of means to determine whether there is a significant difference among sites. The bovine contamination index (BCI) per animal was measured as well as the overall BCI within each area.

\section{Bovine contamination index}

The number of S. japonicum eggs excreted by each bovine, on average, was calculated through the formula, as used by Gordon et al. (2012) and Tenorio and Molina, (2020). 
$\boldsymbol{B C I}=($ Arithmetic mean of eggs per gram $(\mathrm{MEPG})$

$\times$ (number of infected bovines)

$\times 25,000$ g (average fecal weight $)$.

\section{Results}

\section{Prevalence of Schistosoma infection in Oncomelania snails}

Of the six ricefield areas in Lake Mainit, an overall $21.45 \%$ (95\% CI 17.12-25.78) prevalence rate of Schistosoma infection from Oncomelania snails was observed. Among ricefield stations, Alipao had the highest prevalence rate, followed by San Isidro, Matin-ao, Poblacion, and Magpayang, respectively. Differences in the prevalence of Schistosoma in Oncomelania snail per sampling site were significant at $\mathrm{p}=0.0001$ (Table 1). No Oncomelania snails were collected from the ricefields of Cuyago apparently as an outcome of mollusciciding activities in rice fields in previous months. However, thirty (30) Oncomelania individuals were collected near a stream/ carabao grazing area approximately $1 \mathrm{~km}$ from the ricefields. Cercarial shedding from these snails showed a $13.33 \%$ (95\% CI 1.17-25.5) prevalence rate of schistosome infection.

\section{Prevalence of Schistosoma eggs infection in Bovine Fecal Samples}

Fecal samples from bovines in the ricefields of Cuyago were found to harbor Schistosoma eggs with a prevalence of 50\% (95\% CI 9.99-90.01) followed by Alipao 33.3\% (95\% CI 9.67-70). Zero prevalence of schistosome infection was seen from bovine feces from the rice field sites of Poblacion, Magpayang, San Isidro, and Matin-ao. The differences of prevalence and intensity of Schistosoma in bovines among sites were significant at $\mathrm{p}=0.031$ and $\mathrm{p}=0.035$ respectively (Table 2 ). The geospatial data incorporating prevalence of infection for both bovines and snails show the risk of exposure to the disease in ricefields mostly through infected snails in Alipao, Alegria, Magpayang, San Isidro, and Matin-ao. The occurrence of active transmission through the bovine reservoir host and snails from ricefields only occurred in Alipao. No snails were collected from Cuyago but fecal samples from bovines grazed away from the ricefields contained $S$. japonicum eggs.

\section{Bovine contamination index $(\mathrm{BCI})$}

Calculations of the bovine contamination index from this study showed that on average, infected bovines in key rice fields of Lake Mainit could excrete an average index of 55,000 S. japonicum eggs as deposited in the environment each day (Table 3 ). In terms of mean eggs per gram, bovine infection of schistosome can be considered as light infection for Cuyago (1.40) and Alipao (0.80).

\section{Discussion}

Schistosomiasis in Lake Mainit was first recorded in 1947 (Pesigan 1947) and is considered a prevailing endemic public health concern that is endemic to Caraga and 11 other regions in the Philippines (Olveda et al. 2014; Leonardo et al. 2016). In 2016, an inventory of snails, their abundance, and preferred nidus in Lake Mainit show that many snail species, including $O$. quadrasi with potential roles in zoonosis, inhabit ricefields (Jumawan et al. 2016). The ricefield is a key habitat for human transmission of schistosomiasis when infected snails are present and farmers utilize these fields unprotected. Oncomelania harboring $S$. japonicum was reported in some ricefields near Lake Mainit (Abao-Paylangco et al. 2019). However, the current findings indicate that the proximity of infected snail and reservoir hosts in ricefields does not always translate to

Table 1 Prevalence of Schistosoma recorded from Oncomelania snails in the ricefields of Lake Mainit, Philippines

\begin{tabular}{llll}
\hline Sites & Snails screened & No. of infected snails & Prevalence $(\%)(\mathrm{CI} * *)$ \\
\hline Alipao & 68 & 27 & $39.71(28.08-51.33)$ \\
Poblacion, Alegria & 60 & 9 & $15(5.97-24.03)$ \\
Cuyago & $0^{*}$ & $0 *$ & $0 *$ \\
Magpayang & 40 & 1 & $2.50(0.0-7.34)$ \\
San Isidro & 60 & 17 & $28.30(16.93-39.73)$ \\
Matin-ao & 87 & 16 & $18.40(10.25-26.53)$ \\
Over-all & 345 & 74 & $21.45(17.12-25.78)$ \\
\hline
\end{tabular}

*A grazing area away from ricefields contained Oncomelania with $13.33 \%$ (95\% CI 1.17-25.5) prevalence of schistosome infection ** $95 \%$ CI 
Table 2 Prevalence of Schistosoma and intensity of infection in bovines in the ricefields of Lake Mainit

\begin{tabular}{|c|c|c|c|c|}
\hline Sites & No. of samples $(\mathrm{N}=34)$ & No. of infected & Prevalence $(\%)\left(\mathrm{CI}^{* *}\right)$ & Mean Intensity (egg/host) \pm S.E.M. $(p=0.035)$ \\
\hline Alipao & 6 & 2 & $33.3(9.67-70)$ & $1 \pm 0.49$ \\
\hline Poblacion, Alegria & 6 & 0 & 0 & 0 \\
\hline Cuyago & 6 & 3 & $50(9.99-90.01)$ & $2 \pm 0.54$ \\
\hline Magpayang & 4 & 0 & 0 & 0 \\
\hline San Isidro & 6 & 0 & 0 & 0 \\
\hline Matin-ao & 6 & 0 & 0 & 0 \\
\hline
\end{tabular}

** $95 \%$ CI

Table 3 Schistosoma Bovines Contamination index (BCI) for carabaos in ricefields of Lake Mainit calculated using the arithmetic MEPG of the FEA-SD data

\begin{tabular}{lllll}
\hline Sites & Mean EPG & No. of infected & BCI Overall & BCI per bovine \\
\hline Alipao & 0.8 & 2 & 40,000 & 20,000 \\
Poblacion, Alegria & 0 & 0 & 0 & 0 \\
Cuyago & 1.4 & 3 & 105,000 & 35,000 \\
Magpayang & 0 & 0 & 0 & 0 \\
San Isidro & 0 & 0 & 0 & 0 \\
Matin-ao & 0 & 0 & 0 & 0 \\
Overall & 0.17 & 5 & 145,000 & 55,000
\end{tabular}

${ }^{*}$ Calculated using $25 \mathrm{~kg}$ as the daily fecal output for bovines (Gordon et al. 2011: Tenorio and Molina. 2020)

bovine infection. Nonetheless, the proximity could increase the risk of exposure and the underlying danger of exposure of humans to Schistosoma since infection can still occur with or without the bovine reservoir host so long as $\mathrm{On}$ comelania harboring Schistosoma is present. The FEA-SD has high diagnostic sensitivity and can detect high and low intensity of infections, giving a more accurate estimation of infection intensity, better than miracidial hatching test (MHT) and Kato Katz (KK) (Gordon et al. 2012). However, there is a possibility that the zero prevalence observed in some of the sample sites may be due to the limited number of fecal samples in ricefields. Substantial efforts in the search of all possible nidus have been exhausted in all ricefield stations, however, some farmers may have gradually adapted the modern agricultural practice using mechanized plowing, or, may have grazed their bovines further away from ricefields.

It is noteworthy that while Oncomelania did not harbor any schistosome cercariae from the ricefields of Cuyago, the bovines in this area had the highest infection rate which shows proof that ricefields may not be the only source of infection for bovines and other areas such as those for grazing, and resting of the animal may be potential venues for schistosomiasis for this animal. Infection with Schistosoma japonicum in both intermediate hosts and reservoir hosts do not necessarily develop synchronously with each other but rather it takes time for a host to manifest the infection under certain conditions that might include the host's resistance to infection, age, nutrition and domestication (Legaspino et al. 2014; Tenorio and Molina 2020).

Human contact with cercariae-infested water causes Schistosoma infection. People are infected during routine agricultural, domestic, occupational, and recreational activities, which expose them to infested water. In Lake Mainit, the most frequent domestic activities are fishing, bathing, and washing clothes while the most frequent recreational activities are playing and swimming, as the lake has tourism potential. The lake is surrounded by agricultural lands utilized for planting rice and corn. During rainy months, most ricefields get overly flooded with high potential of displacement of infected $O$. quadrasi snails, miracidia from bovine feces, and the spread of freeswimming cercaria to a wider area. This typical scenario in most lakes and marshland regions increases the risk factors for the disease. In China, more than $80 \%$ of schistosomiasis patients live in the lake and marshland regions (Hong et al. 2013) and areas within the Yangtze River (Balen et al. 2007).

In rice-growing areas, such as the surrounding topography of Lake Mainit, bovines are important farm animals and can be a suitable sentinel animal for schistosomiasis surveillance (Angeles et al. 2015) aside from the presence 

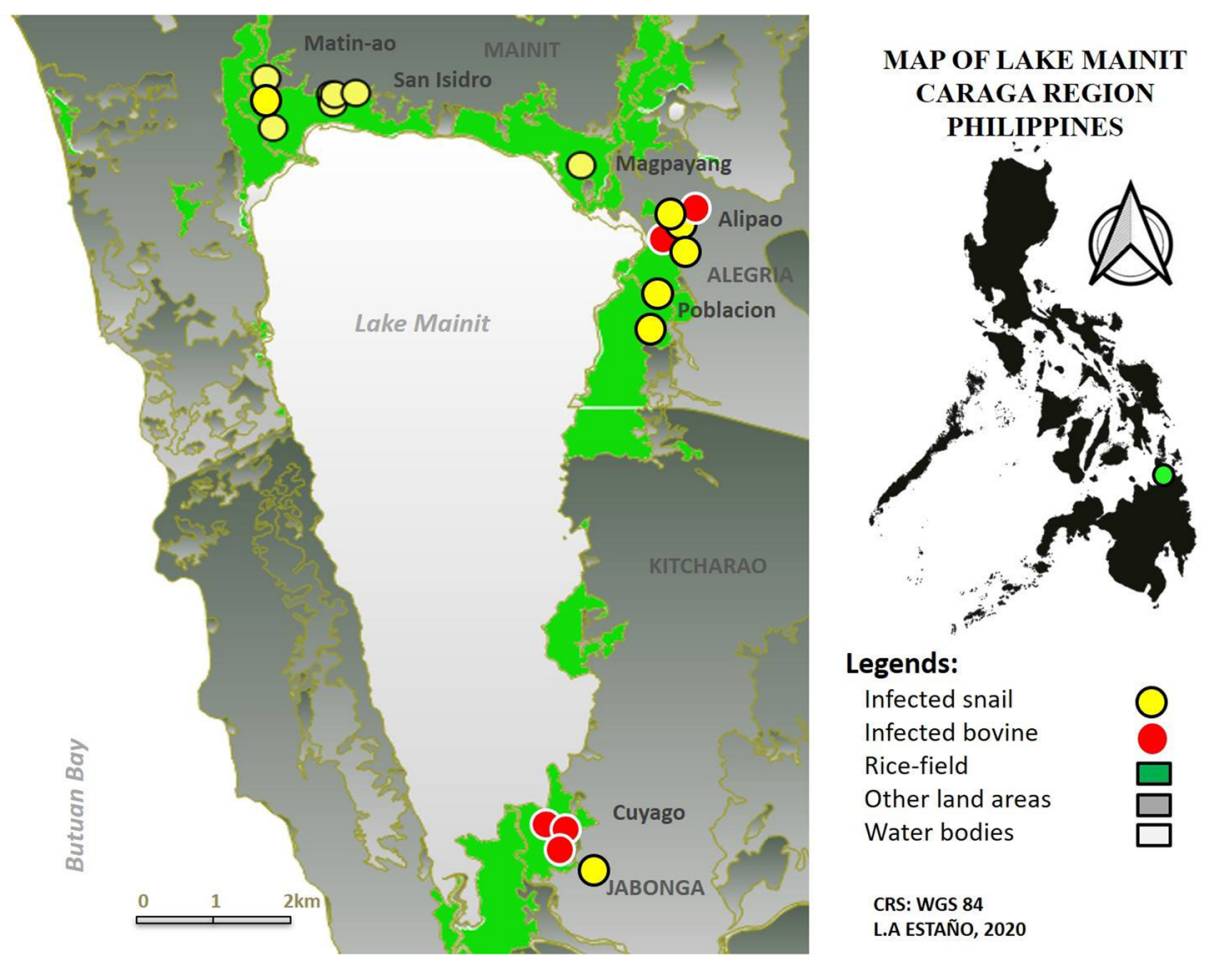

Fig. 2 Spatial distribution of Schistosoma infection in Oncomelania hupensis quadrasi and bovines in the rice-fields of Lake Mainit, Philippines

of infected $O$. quadrasi. Bovines are the major animal reservoirs contributing to human transmission of $S$. japonicum in ricefields because they are repeatedly exposed to the parasite when pulling plows in rice paddies (Yang et al., 2013). Apart from its role in zoonosis, parasitism in bovines affects the animal's fertility and productivity in terms of economic importance (Portugaliza et al. 2018; Tenorio and Molina 2020). A high prevalence of Fasciola sp. was noted from bovines in Lake Mainit (Jumawan et al. 2020) aside from reports of schistosome infection. Most of these bovines traversed extensive distances for pastures and grazing which increases the high level of risk in acquiring the infective stage of the parasite. Water buffaloes spend much of their time immersed in water bodies where they tend to defecate. This increases the probability of exposure to intermediate hosts and also increases the risk of transmission (Gordon et al. 2011).

Infection of bovines to Schistosoma eggs in this study was categorized as light as it only has 11 total egg counts for all the bovine fecal samples. The BCI of individual bovines from Lake Mainit ricefields was lower compared to a study involving bovines in Samar and Koronadal in the Philippines (Gordon et al. 2011; Tenorio and Molina 2020). The lower bovine contamination index of this study may be attributed to the limited fecal samples found in ricefields and the timing of the Schistosoma life cycle and egg release in the stool of bovines during the time of collection. This low BCI may be accounted for the small number of infected bovines and factors affecting the availability of bovines on-site (e.g. grazing, stall-fed, in search of pastures, the proximity of bovine residence) (Portugaliza et al. 2018; Tenorio and Molina 2020). Accordingly, bovines release approximately 40,000 S. japonicum eggs into the environment daily comparing it to water buffaloes in China which excrete $\sim 120,588$ S. japonicum eggs daily (Gordon et al. 2011). China has since claimed success in eradicating schistosomiasis through widespread mass mobilization of capturing Oncomelania snails infected with $S$. japonicum, together with effective support on water and agricultural conservation projects, has successfully curtailed the epidemic (Gray et al. 2009b; Fan 2012) which might be a challenge in the Philippines due to limited resources for programs related to control and eradication. Apart from differences in topography, the transmission is not seasonal as in China (Olveda and Gray 2019).

In the Philippines, the roles of animal reservoir host in the transmission of schistosomiasis is now recognized and the Department of Agriculture and the Department of Health are currently formulating strategies to control schistosomiasis in animals with the development of a bovine vaccine as one of the major directions (DOH 2018). A vaccine-directed control program, that massively reduces 
prevalence, intensity, and transmission will eventually benefit both human and animal health (You et al. 2018).

\section{Conclusion and Recommendation}

The study reports on the infection link between $O$. hupensis quadrasi and the bovine reservoir hosts in ricefields of Lake Mainit by looking into Schistosoma cercariae and eggs, respectively. Results revealed active transmission of Schistosoma as evident through observations of cercariae shed from snails in five of the six stations studied. While Schistosoma infection among bovines may be considered "light," the results confirm the role of bovines in zoonotic transmission. Nonetheless, the results also suggest that ricefields may not be the only major nidus for schistosomiasis; hence, other habitats utilized by bovines should also be considered in future studies. The results call for immediate health-related policy implementation and support interventions such as bovine vaccination, once available as part of a more integrated control measure to reduce disease burden. An integrated approach to control the disease should include operational components such as adequate water supply and sanitation, environmental management, snail control, and health education, in addition to chemotherapy (Praziquantel) and vaccination.

Acknowledgements The study was funded by the Department of Science and Technology - Philippine Council for Health Research and Development (DOST-PCHRD) and the Department of HealthCaraga (DOH-Caraga) through Caraga Health Research and Development Consortium (CHRDC). The authors are indebted to RJ Fornillos of the University of the Philippines-Diliman for confirming our snail samples and to the various Local Government Units (LGUs) of Mainit, Alegria, Jabonga for facilitating the safe collection of the specimen during the time of the COVID-19 pandemic. MK Balamad, R Nepa, M. Cubillas, K Mongado, and S. Besin are acknowledged for their assistance in field and laboratory analyses.

Author contributions JCJ secured funding and supervised the project. JCJ and LAE performed the collection of samples and laboratory analysis as well as the writing of the paper. All authors read and approved the final manuscript.

\section{Declarations}

Conflict of interest The authors declare no conflict of interest.

Ethical approval Wildlife Gratuitous Permit (WGP) R13-2019-65 of the Department of Environment and Natural Resources (DENR) as secured before the collection of snails.

\section{References}

Abao-Paylangco RA, Balamad MKM, Paylangco JC, Japitana RA, Jumawan JC (2019) Schistosoma japonicum in selected ricefields surrounding Lake Mainit Philippines. J Eco Sci Eco-Gov 1(1):15-24

Angeles JMM, Leonardo LR, Goto Y, Kirinoki M, Villacorte EA, Hakimi H, Moendeg KJ, Lee S, Rivera PT, Inoue N, Chigusa Y, Kawazu S (2015) Water buffalo as sentinel animals for schistosomiasis surveillance. Bull World Health Organ 93:511-512. https://doi.org/10.2471/BLT.14.143065

Balen J, Zhao ZY, Williams GM, McManus DP, Raso G, Utzinger J, Zhou J, Li, YS (2007). Prevalence, intensity and associated morbidity of Schistosoma japonicum infection in the Dongting Lake region, China. Bulletin of the World Health Organization, 85, 519-526. https://doi.org/10.2471/BLT.06.034033

Carabin H, Balolong E, Joseph L, McGarvey ST, Johansen MV (2005) Estimating sensitivity and specificity of a faecal examination method for Schistosoma japonicum infection in cats, dogs, water buffaloes, pigs, and rats in Western Samar and Sorsogon Provinces, The Philippines. Int Jour Parasitol 35:1517-1524. https://doi.org/10.1016/j.ijpara.2005.06.010

Cassion CC, Pingal ET, Maniago RB, Medina JRC, Belizario VYJr, (2013) Schistosomiasis and soil-transmitted helminth infections in schoolchildren in the Lake Mainit area in northeastern Mindanao: an opportunity for integrated helminth control in the school setting. Act Med Phil 47(3):4-10

Colley DG, Bustinduy AL, Secor WE, King CH (2014) Human schistosomiasis. Lancet 383(9936):2253-2264. https://doi.org/10.1016/S0140-6736(13)61949-2

Demetillo M, Lador R, Seronay R (2016) Floral assessment in Lake Mainit watershed, Caraga Region, Mindanao, Philippines. Ann Stud Sci Hum 12:12-28

Department of Health (2018) Schistosomiasis Control Program. https://www.doh.gov.ph/schistosomiasis-control-program. Date Accessed 28 Aug 2020

Fan KW (2012) Schistosomiasis control and snail elimination in China. Am J Pub Heal 102(12):2231-2232. https://doi.org/10.2105/AJPH.2012.300809

Fenandez TJ Jr, Tarafder MR, Balolong E Jr, Joseph L, Willingham IAL, Belisle P, Webster JP, Olveda RM, McGarvey ST, Carabin H (2007) Prevalence of Schistosoma japonicum infection among animals in fifty villages of Samar Province, the Philippines. VecBor and Zoon Dis 7(2):147-155. https://doi.org/10.1089/vbz.2006.0565

Frandsen F, Christensen NO (1984) An introductory guide to the identification of cercariae from African freshwater snails with special reference to cercariae of trematode species of medical and veterinary importance. Act Trop 41:181-202

Gordon C, Acosta L, Gray D, Olveda R, Jarilla B, Ross A, McManus D (2012) High prevalence of Schistosoma japonicum infection in carabao from Samar Province, the Philippines: Implication for Transmission and Control. PLoS Negl Trop Dis 6(9):e1778. https://doi.org/10.1371/journal.pntd.0001778

Gray DJ, Williams GM, Li YS, Chen HG, Forsyth S (2009a) The role of bovines in human Schistosoma japonicum infection in the People's Republic China. Am J Trop Med Hyg 81:1046

Gray DJ, Williams GM, LiY CH, Forsyth SJ, Li RS, Barnett AG, Guo J, Ross AG, Feng Z, McManus DP (2009b) A clusterrandomised intervention trial against Schistosoma japonicum in the Peoples' Republic of China: bovine and human transmission. PLoS ONE 4(6):e5900. https://doi.org/10.1371/journal.pone.0005900

Hong XC, Xu XJ, Chen X, Li YS, Yu CH, Yuan Y, Chen Y, Li R, Qiu J, Liu Z, Yi P, Ren GH (2013) Assessing the effect of an integrated control strategy for schistosomiasis japonica emphasizing bovines in a marshland area of Hubei Province, China: a cluster randomized trial. PLoS Negl Trop Dis 7(3):e2122. https://doi.org/10.1371/journal.pntd.0002122 
Jumawan JC, Estaño LA, Siega GH, Maghinay KA, Santillan MM, Jumawan JH (2016) Gastropod fauna in key habitats surrounding Lake Mainit, Philippines with notes on snail-associated diseases. AACL Bioflux 9(4):864-876

Jumawan JC, Balamad MKM, Estaño LA (2020) Zoonotic Transmission and Infection from Bovine Feces in Selected Ricefields of Lake Mainit, Philippines. As J Biol Li Sci. 9(2):185-189. https://doi.org/10.5530/ajbls.2020.9.28

Kariuki HC, Clennon JA, Brady MS, Kitron U, Sturrock RF, Ouma JH, Pellegrini C (2004) Distribution patterns and cercarial shedding of Bulinus nasutus and other snails in the Msambweni area, Coast Province, Kenya. The Am J Trop Med Hyg 70(4):449-456. https://doi.org/10.1017/S0031182006001594

Legaspino RT, Metillo E, Claveria F (2014) Distribution of Oncomelania quadrasi (Mollendorf 1895) and Prevalence of Infected Snails in Schistosomiasis Endemic Villages of Kapatagan and Lala, Lanao del Norte, Philippines. Int J Ecol Cons 11:87-109. https://doi.org/10.7718/ijec.v11i1.809

Leonardo L, Rivera P, Saniel O, Solon JA, Chigusa Y, Villacorte E, Chua JC, Moenderg K, Manalo D, Crisostomo B, Sunico L, Boldero N, Payne L, Hernandez L (2013) New Endemic foci of Schistosomiasis infections in the Philippines. Act Trop. https://doi.org/10.1016/j.actatropica.2013.03.015

Leonardo L, Chigusa Y, Kikuchi M, Kato-Hayashi N, Kawazu S, Angeles J, Fontanilla IK, Tabios IK, Moendeg K, Goto Y, Fornillos RJ, Tamayo IG, Chua JC (2016) Schistosomiasis in the Philippines: challenges and some successes in control. SE As J Trop Med 47(4):651-666

LMDA (Lake Mainit Development Authority) 2005 Lake Mainit Fisheries Resource Assessment Preliminary Investigation Report 137 pp. Date Accessed:24 Aug 2020

McManus DP, Gray DJ, Ross AG, Williams GM, He HB, Li YS (2011) Schistosomiasis research in the dongting lake region and its impact on local and national treatment and control in China. PLoS Negl Trop Dis 5(8):e1053. https://doi.org/10.1371/journal.pntd.0001053

Olveda RM, Gray DJ (2019) Schistosomiasis in the Philippines: Innovative Control Approach is Needed if Elimination is the Goal. Trop Med Infect Dis 4:66. https://doi.org/10.3390/tropicalmed4020066

Olveda DU, Yuesheng L, Olveda RM, Lam AK, McManus DP, Chau, TNP, Harn DA, Williams GM, Gray DJ, Ross, AGP (2014)
Bilharzia in the Philippines: past, present, and future. Elsevier Limited Company, https://doi.org/10.1016/j.ijid.2013.09.011

Opisa S, Odiere M, Jura W, Karanja D, Mwinzi P (2011) Malacological survey and geographical distribution of vector snails for schistosomiasis within informal settlements of Kisumu City, western Kenya. Par \& Vec, 4:226. https://doi.org/10.1186/1756-3305-4-226

Pesigan TP (1947) Result of brief schistosomiasis survey around Lake Mainit, Mindanao. J Phil Med Ass 23(1):23-32

Portugaliza HP, Balaso IMC, Descallar JCB (2018) Lañada EB (2018) Prevalence, risk factors, and spatial distribution of Fasciola in carabao and intermediate host in Baybay, Leyte, Philippines. Vet Parasitol Regional Stud Rep 15:100261. https://doi.org/10.1016/j.vprsr.2018.100261

Riley S, Carabin H, Bélisle P, Joseph L, Tallo V, Balolong E, Willingham AL III, Fernandez TJ Jr, Gonzales RON, Olveda R, McGarvey ST (2008) Multi-host transmission dynamics of Schistosoma japonicum in Samar province, the Philippines. PLoS Med 5(1):e18. https://doi.org/10.1371/journal.pmed.0050018

Tenorio JCB, Molina EC (2020) Schistosoma japonicum infections in cattle and water buffaloes of farming communities of Koronadal City ,Philippines. Int J One Health 6(1): 28-33. https://doi.org/10.14202/IJOH.2020.28-33

$\mathrm{Xu} \mathrm{B}$, Gordon CA, Hu W, Mcmanus DP, Chen H, Gray DJ, Ju C, Zeng XJ, Gobert GN, Ge J, Lan WM, Xie SY, Jiang WS, Ross AG, Acosta LP, Olveda R, Feng Z (2012) A novel procedure for precise quantification of Schistosoma japonicum eggs in bovine feces. PLoS Negl Trop Dis 6(11):e1885. https://doi.org/10.1371/journal.pntd.0001885

Yang K, Li W, Sun LP, Huang YX, Zhang JF, Wu F, Hang DR, Steinmann P, Liang YS (2013) Spatio-temporal analysis to identify determinants of Oncomelania hupensis infection with Schistosoma japonicum in Jiangsu province. China Par Vec 6(1):138. https://doi.org/10.1186/1756-3305-6-138

You H, Cai P, Tebeje BM, Li Y, McManus DP (2018) Schistosome vaccines for domestic animals. Trop Med Infect Dis 3(2):68. https://doi.org/10.3390/tropicalmed3020068

Publisher's Note Springer Nature remains neutral with regard to jurisdictional claims in published maps and institutional affiliations. 